\title{
Benign ve malign tiroit hastalıklarında radyoaktif iyot tedavisi
}

\section{Radioiodine therapy in benign and malignant thyroid disorders}

\author{
Murathan Şahin*, Sibel Uçak Semirgin* \\ Ondokuz Mayıs Üniversitesi Tıp Fakültesi, Nükleer Tıp Anabilim Dalı, Samsun, Türkiye
}

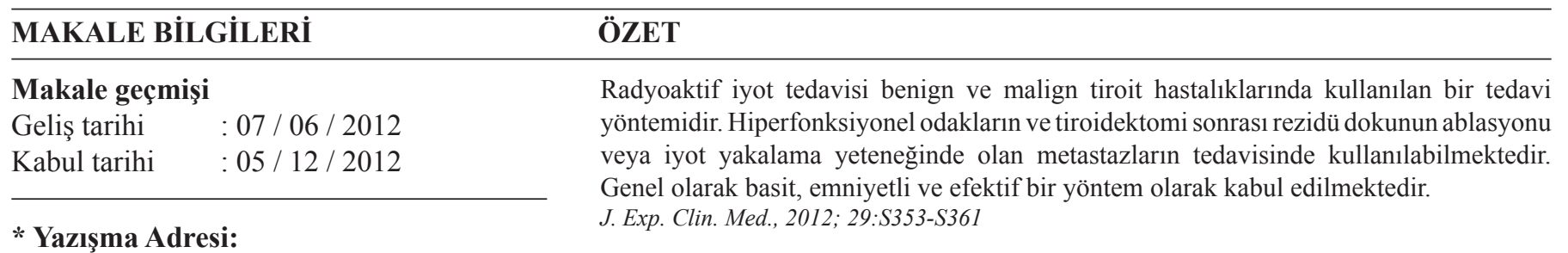

Murathan Sahin

Ondokuz Mayıs Üniversitesi,

Tıp Fakültesi,

Nükleer Tıp Anabilim Dalı,

Samsun

e-posta: murathan@omu.edu.tr

\begin{abstract}
Radioiodine therapy has been an accepted treatment modality of the benign and malignant thyroid disorders. It can be used for the ablation of the hyperfunctioning tissue or postthyroidectomy remnant and treatment of the iodine avid metastases. It is the simplest and safest method of therapy in addition to the effectiveness for most patients.

J. Exp. Clin. Med., 2012; 29: S353-S361
\end{abstract}

\begin{abstract}
Anahtar Kelimeler:
Tiroit kanseri

Graves hastalığ

Otonom toksik nodül

Toksik multinodüler guatr

Nontoksik multinodüler guatr

Radyoaktif iyot tedavisi
\end{abstract}

\author{
Keywords: \\ Thyroid cancer \\ Graves'disease \\ Solitary toxic nodule \\ Toxic multinodular goiter \\ Non-toxic multinodular goiter \\ Radioiodine theraphy
}

(C) 2012 OMU

\section{Giriş}

Alfa ya da beta partikülü yayan radyoaktif maddelerin fizikokimyasal özelliklerine bağlı olarak bazıları taşıyıcı kullanılarak yapılan tedavi "metabolik radyoterapi" olarak adlandirılır (Zimmermann, 2007). Bu amaçla lenfoma tedavisinde kullanılan Yttrium-90 $\left({ }^{90} \mathrm{Y}\right)$ Rituksimab gibi hedefe yönlenmesi taşıyıcı kullanılarak sağlanan radyoaktif maddeler ya da hipertiroidi/iyi diferansiye tiroit kanserlerinde, iyot gibi hedefin metabolizmasında fizyolojik olarak kullanılan maddelerin radyoaktif izotopları kullanılır. İyot (I) atomunun radyoaktif izotoplar1 olan ${ }^{123} \mathrm{I}$ ve ${ }^{124} \mathrm{I}$ in vivo tan1, ${ }^{131} \mathrm{I}$ in vivo tanı/tedavi amaçlı olarak kullanılmaktadır. ${ }^{131}$ I'in fiziksel yarı ömrü 8,04 gün olup stabil izotop olan ${ }^{127}$ I'den dört nötron fazlalığı vardır. Radyoaktif parçalanma esnasında nükleustan elektron atılarak nötron protona dönüşürken stabil Xenon$131\left({ }^{131} \mathrm{Xe}\right)$ oluşur (Kowalsky ve Perry, 1987). Nükleustan atılan bu elektron negatif yüklü beta partikülü ya da negatron olarak adlandırılır ve orbital elektrondan (e-) ayırt edebilmek için $\beta$ - olarak gösterilir;

$$
{ }_{53}^{131} \mathrm{I} \rightarrow{ }_{54}^{131} \mathrm{Xe}+\beta-
$$

$\mathrm{I}^{131}$ 'in parçalanması esnasında $971 \mathrm{keV}$ enerji açı̆̆a çıkar. Sıklıkla bunun $607 \mathrm{keV}$ 'u beta partikülü ile geri kalan 364 $\mathrm{keV}$ ise uyarılmış ${ }^{131} \mathrm{Xe}$ nükleusunun bazal enerji seviyesine inerken gama ışını olarak salınımı şeklinde görülür (Kowalsky 
ve Perry, 1987). Beta partikülü çekirdekten atıldıktan sonra dokuda ortalama $0,4 \mathrm{~mm}$ (en fazla $3 \mathrm{~mm}$ ) hareket ederek direkt yolla DNA hasarına ya da kritik makromoleküllerle reaksiyona giren serbest radikallerin oluşumuna neden olarak dolaylı yolla hücrelerin tahrip olmasına neden olur (Stokkel ve ark., 2010). Gama 1şııı, ${ }^{131}$ I'in akümüle olduğu doku ve organların gama kameralarda görüntülerinin alınmasını sağlar.

Oral yolla alımını takiben bir saat içinde ${ }^{131} \mathrm{I}^{\prime}$ in $\% 90^{\prime} 1$ emilir (Elgazzar ve Al-Bader, 2006). Verilen aktivitenin yaklaşı \% 20'si tiroit bezinde foliküler hücreler tarafindan yakalanır ve organifiye edilir. Ancak hipertiroidide bu oran artmakta ve bazı olgularda \% 90'a kadar çıkabilmektedir (Stokkel ve ark., 2010). Küçük bir bölümü ise tükrük bezleri, mide mukozas1, koroid pleksus, hamilelerde plasenta ve emzirenlerde sütte bulunur. Verilen aktivitenin büyük bölümü (\% 75) idrar ile atılırken \% 10'a varan düzeyler bağırsaklarla ekskrete edilir (Elgazzar ve Al-Bader, 2006).

\section{Benign tiroit hastalıkları}

Graves hastalı̆̆ 1 , toksik multinodüler guatr (TMG), soliter toksik nodül (STN), nontoksik multinodüler guatr (NTMG), guatr rekürrensi ve cerrahi sonrası malign oftalmopati olgularında (inaktif durumda) rezidü tiroit dokusunun ablasyonu amaciyla ${ }^{131} \mathrm{I}$ ile radyoaktif iyot (RAİ) tedavisi yapılabilir (Stokkel ve ark., 2010). Hipertiroidi hastalarının tedavisinde yaklaşık 70 yıldır ${ }^{131} \mathrm{I}$ kullanılmaktadır (Hertz ve Roberts, 1942). Tedavinin biyolojik temeli RAI'un tiroit bezinde konsantre olması ve radyasyona bağl hasar nedeniyle folikül hücre fonksiyonlarının inhibisyonudur. Tedavinin etkinliği tiroit bezi iyot alımı, bezin ağırlı̆̆ı, iyotun biyolojik yarı ömrü ve dokuda dağılımı, foliküllerin radyosensitivitesi gibi bazıları hesaplanabilir faktörlere bağlıdır. Tiroit iyot uptake değeri kullanılarak her bir gram tiroit dokusu başına verilen aktivitenin veya tiroidin absorbe edeceği radyasyon dozunun belirlenmesi ile doz hesabı matematiksel olarak yapılabilir. Diğer yöntem "sabit doz" kullanımı olup bezin palpasyonla büyüklüğünün saptanması veya ultrasonografi/ sintigrafi ile boyutlarının belirlenmesi esasına göre doz belirlenir. Siklikla tedavide kullanılan doz 400-600 MBq (10$16 \mathrm{mCi}$ ) arasında değişir (Stokkel ve ark., 2010). Gram başına aktivite ya da absorbe edilen radyasyon yöntemleri ile yapılan doz hesaplama ile sabit doz metodu arasında tedavi etkinliği ve hipotiroidi gelişme insidansı bakımından anlamlı fark yoktur (Gupta ve ark., 2010). Bu nedenle yaygın olarak aynı zamanda daha düşük maliyetli olan sabit doz metodu kullanılmaktadır.

Tedavi öncesi tirostatik ilaç kullanımı tiroit hormon stoklarını azaltması nedeniyle RAİ tedavisine bağlı olarak folikül hasarı nedeniyle kana geçebilecek hormon düzeyini azaltır. Bu da tedavinin güvenle yapılmasını sağlar. Ancak RAI'un tiroit bezinde alımını azaltması ve muhtemelen hücreleri radyasyondan koruyucu etkileri nedeniyle tedavinin etkinliğini de azalatabilir. Metimazol ve karbimazol tedaviden iki gün öncesine kadar kullanılabilirken propil tiyourasilin 2-3 hafta önce kesilmesi ya da tüm antitiroit ilaçların 5-7 gün önce kesilmesinin yeterli olacağı bildirilmektedir (Stokkel ve ark., 2010; Henkin ve ark., 2011). Ancak bu dönemde hipertiroidi semptomlarını azaltmaya yönelik olarak beta adrenerjik blokerler kullanılabilir.

Radyoaktif iyota karşı alerjik reaksiyon oluşmamaktadır.
Çünkü $10 \mathrm{mCi}{ }^{131} \mathrm{I}$ 'deki iyot miktarı 0,81 mikrogram olup birkaç yüz mikrogram olan günlük besinlerle aldığımız iyot ile karşılaştırıldığında oldukça düşüktür (Meier ve ark., 2006).

Graves hastalığı tedavisinde RAİ kullanımı Amerika Birleşik Devletleri'nde en fazla tercih edilen tedavi yöntemidir (Wartofsky ve ark., 1991). Önerilen doz 10-15 mCi RAİ kullanımıdır (Bahn ve ark., 2011). Gerektiğinde tekrarlamak üzere düşük dozların kullanımı ya da yüksek ablasyon dozunda aktivite verilmesi diğer tedavi yaklaşımlarıdır (Meier ve ark., 2006). RAİ tedavisinde önceleri ötiroidi amaçlanmakta ve hipotiroidi komplikasyon olarak değerlendirilmekte iken günümüzde ötiroidi veya hipotiroidinin sağlanması tedavi olarak kabul edilmektedir (Şek. 1) (Stokkel ve ark., 2010; Bahn ve ark., 2011).

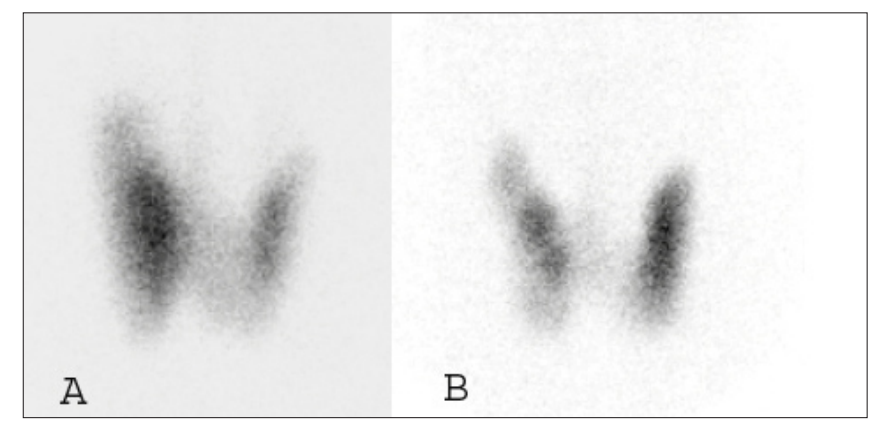

Şek. 1. Graves hastalığı. 43 yaşında kadın hastanın $(\mathrm{TSH}=0,06) \mathrm{Tc}-99 \mathrm{~m}$ perteknetat tiroit sintigrafisinde tiroit bezi diffüz hiperaktif görünümdedir (A). $370 \mathrm{MBq}(10 \mathrm{mCi})$ RAİ tedavisinden üç ay sonra hasta hipotiroidik $(\mathrm{TSH}=10,95)$ olup tiroit bezinin aktivitesi heterojen tarzda azalmıştır (B).

Yüksek dozların seçimi hızla hipertiroidinin kontrolü, seyrek rekürrens ve daha erken başlayan yüksek insidans hipotiroidiye neden olurken düşük dozlar hastalık kontrolünde güçlüğe neden olabilmekte ve yeniden tedavi gerektirebilmektedir. Doz seçiminde tiroit bezi büyüklüğü, hipertiroidinin hızla kontrol edilmesinin gerektiği başka hastalık varlığı gibi faktörler göz önüne alınarak en uygun doz saptanmalıdır. Tedaviden bir yıl sonra başarı oranları $10 \mathrm{mCi}$ RAİ ile tedavi edilenlerde \% 69-90, $15 \mathrm{mCi}$ ile tedavi edilenlerde ise \% 79-90 olarak gösterilmiştir (Von Hofe ve ark., 1978; Canadas ve ark., 2007; Collier ve ark., 2009). $15 \mathrm{mCi}$ ile tedavi edilenlerin $\% 75$ 'inde altı ay sonra hipotiroidi gelişmektedir (Peters ve ark., 1995). Seçilecek doz hipotiroidinin başlangıç zamanını değiştirebilir ancak bir yıldan sonra hipotiroidi insidansı dozdan bağımsız olarak yıllık \% 3-5 arasında artış göstermektedir (Meier ve ark., 2006). Düşük doz ile tedavi edilenlerde dahi uzun dönemde hipotiroidi oluşmakta olup $6,3 \mathrm{mCi}$ veya $9,4 \mathrm{mCi}$ ile tedavi edilenlerde ortalama 80 ay süren takip sonras $\% 69$ hipotiroidi, \% 4 ötiroidi saptanmıştır (Leslie ve ark., 2003). RAI'a bağlı hücre hasarı haftalarca devam eden kademeli bir süreç olduğundan tedavi etkinliği veya yeniden tedavi kararı üç aydan evvel verilmemeli, tercihen 6. aydan sonra verilmelidir.

Graves hastalığında RAİ ile tedavi edilenlerde oftalmopati oluşumu ya da oftalmopatinin kötüleşmesi riski antitiroit ilaç tedavisi ya da cerrahi tedaviye göre daha fazladır (Tallstedt ve ark., 1992). Aktif olmayan oftalmopati olgularında RAİ 
tedavisi uygulanabilir. Aktif fazda olup European Group on Graves' Orbitopathy (EUGOGO) kriterlerine göre hafif oftalmopatili olgularda ise RAİ tedavisi oral kortikosteroid uygulaması ile birlikte yapılabilir (Bartalena ve ark., 2008; Bahn ve ark., 2011). Sigara içenlerde oftalmopati gelişimi riski daha fazladır (Stokkel ve ark., 2010). Bunlarda mutlak gereklilik olmamakla birlikte oral kortikosteroid kullanılabilir.

Soliter toksik nodül ve toksik multinodüler guatrda, nodül/ nodüller dışı tiroit alanları tiroit stimüle edici hormonun (TSH) süprese olması nedeniyle hipofonksiyon gösterdiğinden RAİ çoğunlukla nodülde akümüle olur, normal hücreler ${ }^{131} \mathrm{I}$ 'in destrüktif etkilerinden korunur. Bu nedenle tedaviden sonra birçok hastada ötiroidi sağlanabilir (Şek. 2,3).

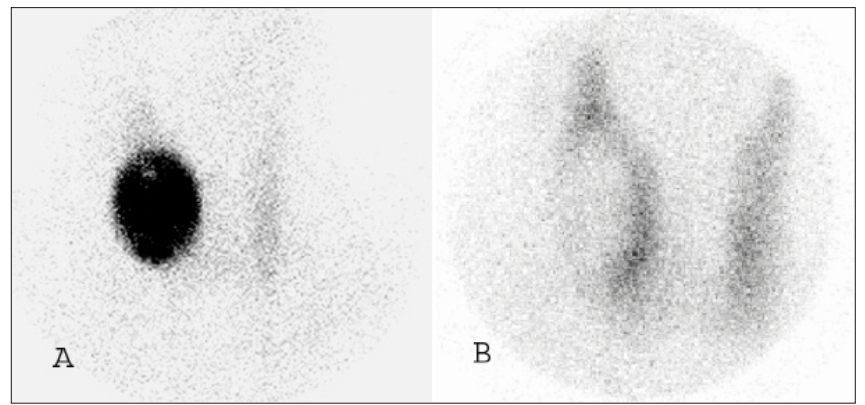

Şek. 2. Otonom toksik nodül. 51 yaşında erkek hastanın $(\mathrm{TSH}=0,002 \mu \mathrm{IU} / \mathrm{mL}) \mathrm{Tc}-99 \mathrm{~m}$ perteknetat tiroit sintigrafisinde sağ tiroit lobunda büyük boyutlarda hiperaktif nodül (İnce iğne aspirasyon biyopsisi (İIAB): Malignite negatif) ve nodül dışı alanlarda süpresyon vardır (A). $740 \mathrm{MBq}(20 \mathrm{mCi})$ dozunda RAI tedavisinden üç ay sonra hastanın ötiroit olduğu $(\mathrm{TSH}=1,05)$ ve sağ lobtaki nodülün hipoaktif hale döndüğü izlenmektedir (B).

Ancak birinci dozdan sona hipertiroidi tedavi edilmezse süpresyonun azalması nedeniyle ikinci ya da üçüncü dozlar nodül dışı alanlarda da ${ }^{131}$ I'in akümüle olmasına neden olacağından hipotiroidi riski artar. Hastaların ortalama 20 ay süre ile takip edildiği bir çalışmada RAİ ile tedavi edilen STN hastalarının \% 100'ünde, TMG hastalarının ise \% 88'inde hipertiroidi tedavi edildi (Porterfield ve ark., 2008).

RAİ ile hipertiroidinin tedavisi yanı sıra tiroit volümünde de üç ayda \% 35'e varan azalma saptandı (Nygaard ve ark., 1999). Hiperaktif nodüller tedaviye daha dirençli olduğundan Graves hastalığı ile karşılaştırıldığında daha yüksek dozların verilmesi gerekir. Kullanılabilen dozlar 5-30 mCi arasında olmakla birlikte genellikle fiks doz olarak 10-20 mCi RAİ verilmektedir (Iagraru ve McDougall, 2007; Bahn ve ark., 2011). Yüksek dozların seçimi hastaların daha erken tedavi edilmesini sağlarken, uzun dönemde seçilen dozdan bağımsız olarak yüksek başarı oranları elde edilmektedir (Zakavi ve ark., 2009). Ancak doz artımı genellikle hipotiroidi riskini de artırmaktadır. Hastalardan 10,3 mCi doz verilenlerde 4,9 yıllık takip sonrası $\% 6,7 ; 20 \mathrm{mCi}$ doz verilenlerde 10 yıllık takip sonunda $\%$ 6-12; 25-40 mCi verilenlerde ise birinci y1lın sonunda \% 55 oranında hipotiroidi saptanmıştır (Ross ve ark., 1984; Huysmans ve ark., 1991; Tzavara ve ark., 2002; Zakavi ve ark., 2009).

Nontoksik multinodüler guatrda RAİ tedavisi semptomatik olgularda tiroit volümünü azaltmaya yönelik

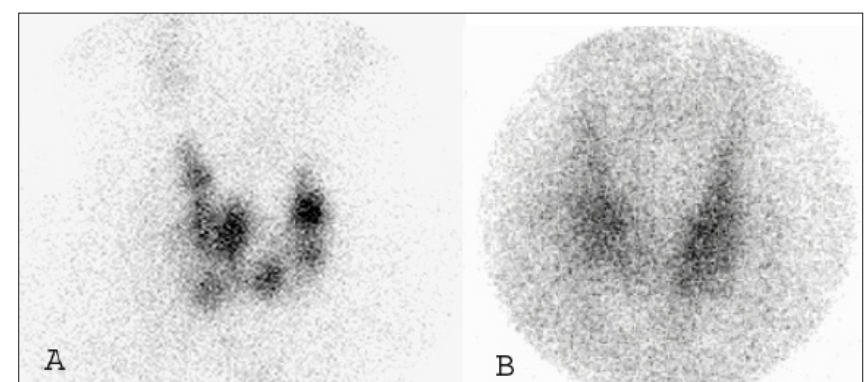

Şek. 3. Toksik multinodüler guatr. 71 yaşında kadın hastanın (TSH=0,19 $\mu \mathrm{IU} / \mathrm{mL}$ ) Tc-99m perteknetat tiroit sintigrafisinde tiroit bezinde en büyüğü sağda isthmus komşuluğunda olmak üzere multipl hiperaktif nodül mevcuttur (A). $740 \mathrm{MBq}(20 \mathrm{mCi})$ RAİ tedavisinden üç ay sonra ötiroidi sağlanmış $(\mathrm{TSH}=2,39)$ olup tiroit sintigrafisinde hiperaktif nodüller izlenmemektedir (B).

olarak kullanılabilir. İleri yaş grubunda bu amaçla yaklaşık 20 yıldır kullanılmaktadır. Kullanılan dozlar TNG'a göre daha yüksektir. Doz 1110 MBq'e (30 mCi) kadar ulaşabilmektedir (Stokkel ve ark., 2010). Tiroit uptake testi sonuçlarına göre doz hesabı yapılmaktadır. Tiroidin her gramı için 14 $\pm 4,2$ MBq (yaklaşık 0,4 mCi) ${ }^{131} \mathrm{I}$ dozundan üç ay sonra \% 42, bir yıl sonra \% 66 oranında tiroit hacminde azalma olduğu gösterildi (Bachmann ve ark., 2009). Rekombinant TSH (rTSH) ile stimulus sonrası daha homojen tiroit bezi dağılımı, bez içindeki göreceli hipoaktif alanlarda artmış ${ }^{131} \mathrm{I}$ alımı ve tedavi etkinliğinde artışlar saptandı (Salvatori ve Luster, 2010). Büyük, kompresyon yapan guatr olgularında da cerrahi tedavi ilk seçenek olmakla birlikte rTSH ile desteklenmiş $\mathrm{I}^{131}$ tedavisinin yeni bir yaklaşım olabileceği bildirilmektedir. Hipertiroidi ya da NTMG'da RAİ tedavisi hamilelik veya laktasyon durumunda, şüpheli tiroit kanseri olgularında ve 4-6 ay içinde hamilelik planlayan kadınlarda uygulanmamalıdır (Bahn ve ark., 2011). Lokal kompresyon bulgusu olanlarda veya hızla ötiroidinin sağlanması gerekenlerde alternatif yöntemlerin seçilmesi uygun olacaktır (Yano ve ark., 2011).

Tedavi uygulamasından 1-3 gün sonra servikal hassasiyet, yutma güçlüğü gibi radyasyon tiroiditine bağlı bulgular görülebilir (Henkin ve ark., 2011). Perinöral ödeme bağl1 vokal kord paralizisi, hipoparatiroidi, hiperparatiroidi nadiren gözlenebilir (Harbert ve ark., 1987). Folikül hücre destrüksiyonu sonucu tiroglobulin ( $\mathrm{Tg}$ ) ve tiroit hormonlarında ilk iki hafta geçici artış olabilir. Tiroit firtınası \% 0,34 insidans ile nadiren görülür (Harbert ve ark., 1987). Hipertiroidiye yönelik RAİ tedavisinin malignite, infertilite veya önceden tedavi edilenlerin çocuklarında doğumsal anomali riskinde artışa neden olmadığı söylenebilir (Ron ve ark., 1998; Read ve ark., 2004; Henkin ve ark., 2011).

\section{Malign tiroit hastalıkları}

Tiroit karsinomlarının \% 70-80'ini papiller karsinomlar oluşturur. Kalanların çoğunluğu foliküler karsinom, daha azı ise medüller veya anaplastik kanserlerden oluşur (Silberstein, 2006). Medüller kanserde RAİ tedavisinin sınırlı yeri vardır. Anaplastik kanserlerde ise RAİ tedavisi uygulanmamaktadır. Papiller ve foliküler karsinomlara iyot alımı göstermesi nedeniyle RAİ uygulaması yapılabilir. Tedavi rezidü tiroit dokusunun ablasyonu veya lokal ya da uzak metastazın tedavisi amacıyla yapılır. Ablasyon postoperatif rezidü tiroit 
dokusunun yok edilmesi için yapılır (Şek. 4). Tedavi ve hastanın takibinde bazı avantajlar sağlar. Tiroit kanseri sıklıkla multifokal olduğundan rezidü dokudaki okkült malign odaklar RAİ ile yok edilebilir. Tüm fonksiyonel dokunun yok edilmesi ile takipte ve rekürrens araştırmasında $\mathrm{Tg}$ düzeyi duyarlı bir yöntem olarak kullanılabilir. Tiroit dokusunun iyot alımı iyi diferansiye de olsa tiroit kanserinden fazla olacağından rezidü dokunun olması verilen iyotun daha çok normal hücreler tarafından yakalanmasına neden olur. Bu nedenle rezidü tiroit dokusu varlığı ${ }^{131}$ I tarama çalışmasının duyarlılığını ve gelecekte olası metastaz durumunda tedavinin etkinliğini azaltıcı faktördür.

Ablasyon için tiroidektomi sonrası kalan rezidü dokunun iki gramı geçmemesi gerekir (Maxon ve Smith, 1990). Rezidü dokunun fazlalığı radyasyon tiroiditi semptomlarının ortaya çıkmasına neden olabilir. Ablasyon için tiroidektomiden en erken 3 hafta sonra TSH düzeyinin $30 \mu \mathrm{IU} / \mathrm{mL}$ düzeyine ulaştığı gösterilmeli

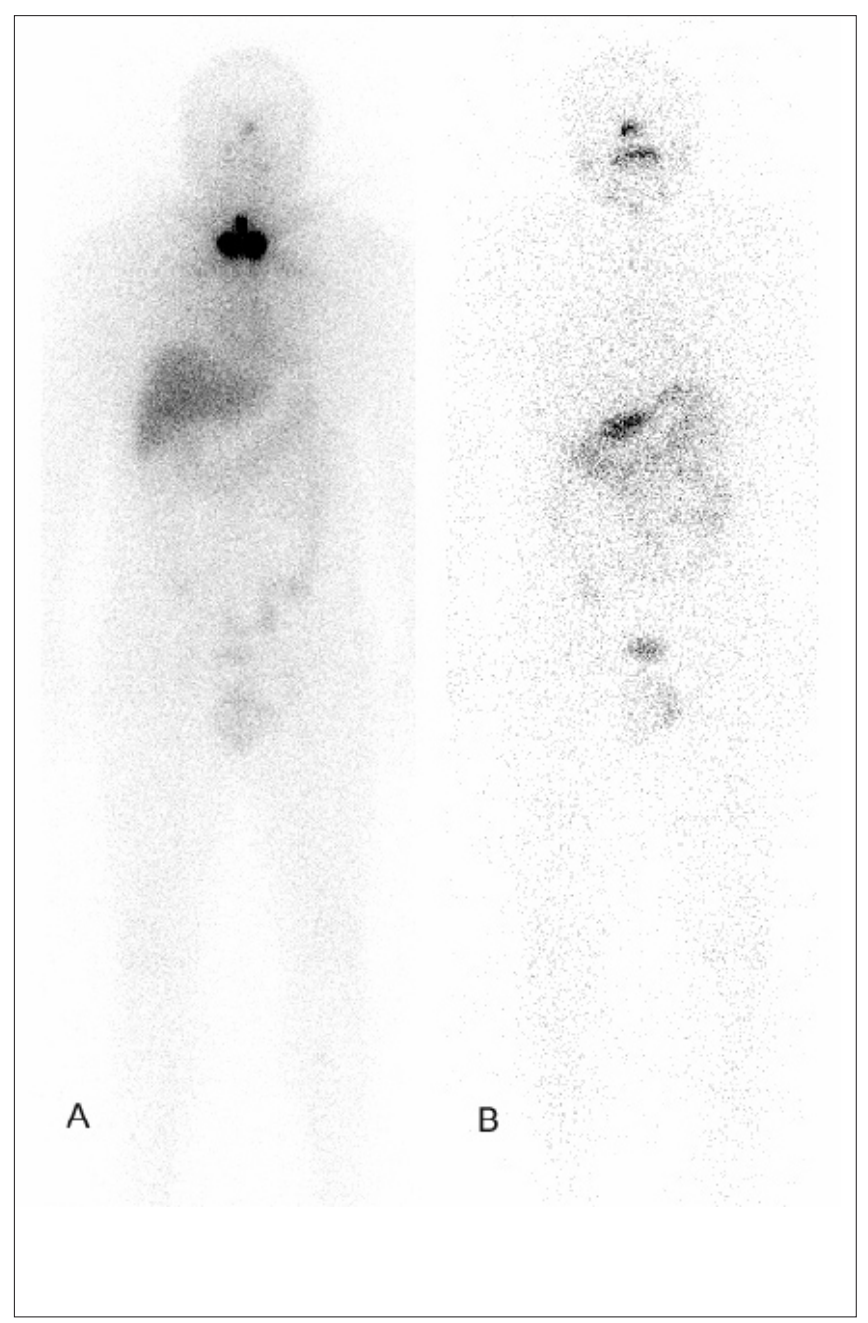

Şek. 4. RAİ ile rezidü tiroit dokusu ablasyonu. Tiroit papiller kanseri nedeniyle tiroidektomi yapılan 43 yaşında erkek hastaya $100 \mathrm{mCi}$ RAİ ile ablasyon yapıldı. Ablasyon dozunun verilmesinden yedi gün sonra yapılan tüm vücut tarama çalışmasında servikal bölgede ${ }^{131}$ I akümüle eden rezidü tiroit dokusu saptandı (A). Diğer ${ }^{131}$ I akümüle eden alanlar fizyolojik olarak değerlendirildi. Ablasyondan altı ay sonra tanısal ${ }^{131}$ I tüm vücut tarama çalışmasında servikal bölgede rezidü doku kalmadığ düzeyinde patolojik odak olmadığı izlendi (B). veya rTSH ile stimulus yapılarak ${ }^{131}$ I uygulanmalıdır (Luster ve ark., 2008). RAİ tedavisi öncesi tiroit hormon replasman tedavisi yapılmamalı veya ${ }^{131}$ I uygulamasından iki hafta önce kesilmek üzere triiyodotironin (LT3) preparatı kullanılmalıdır. Rezidü tiroit doku ablasyonu için 30-100 $\mathrm{mCi}^{131} \mathrm{I}$ kullanılabilir (Cooper ve ark., 2009). Ancak rezidü mikroskopik hastalık ya da agresif tümör varyantlarında doz, 100-200 mCi olmalıdır (Cooper ve ark., 2009). Rezidü doku ablasyonu için $30 \mathrm{mCi}$ kullanıldığında hastaların \% 67'sinde, 25-50 mCi kullanıldığında ise ortalama \% 80 başarı sağlandı (Maxon ve ark., 1992; Bal ve ark., 2004).

rTSH ile ablasyon yapılacaksa 50 mCi'yi geçen dozların kullanılması önerilmektedir (Pitoia ve ark., 2009). Ancak, endojen TSH stimülasyonu veya rTSH ile $50 \mathrm{mCi}$ dozunda RAİ kullanıldığında da benzer ablasyon başarı oranları elde edilmiştir (Chianelli ve ark., 2009). Tiroidektomi sonrası verilen ilk dozun amacı rezidü tiroit dokusu ablasyonu ve takiben yapılan tüm vücut tarama ile ilk evrelemenin yapılabilir olmasıdır. Bunun yanısıra bilinmeyen metastatik odakların tahrip edilmesi ile rekürrens riskinde azalmayı sağlayan "adjuvan tedavi” etkisi sağlanmış olur (Cooper ve ark., 2009). Düşük dozlar rezidü doku ablasyonu için yeterli olabilmekle birlikte tedavinin diğer amacı olan bilinmeyen rezidü malignite/metastatik odakların tedavisinde yetersiz kalabilir. $\mathrm{Bu}$ nedenle doz seçiminde hastanın risk grubu göz önünde tutulmalıdır. Ablasyondan 6-12 ay sonra tanısal dozda ${ }^{131}$ I tüm vücut taraması ile rezidü doku ve varsa metastatik odakların tedaviye yanıtı değerlendirilir. Genel olarak tümör çap $1<1 \mathrm{~cm}$ ve yüksek risk özellikleri taşımayan hastaların tiroidektomi sonrası iyi prognoz göstermesi nedeniyle RAİ ile ablasyon önerilmemektedir (Tablo 1).

Ablasyon öncesi evreleme amaçlı olarak radyoaktif iyot ile tüm vücut tarama çalışması yapılması hastalara tedavi yaklaşımını değiştirebilmektedir. İyi diferansiye tiroit kanserli hastalardan elde edilen preablatif 350 iyot tarama sintigrafisinin hastaların \% 53'ünde klinik yaklaşımı değiştirdiği bildirildi (Nostrand ve ark., 2009). Ancak genel olarak preablatif iyot tarama çalışması yapılmamaktadır. Bunun sebebi bu amaçla kullanılabilecek izotoplardan birisi olan ${ }^{123}$ I'ün her yerde elde edilememesi ve pahalılı̆̆ 1 , pozitron emisyon tomografisi (PET) izotopu olan ${ }^{124}{ }^{1}$ 'ün gelecek vaat etmekle birlikte henüz etkinliğinin tam olarak bilinmemesi ve rutin kullanımı olmaması, ${ }^{131}$ I'in ise tartışmalı olmakla birlikte "stunning" oluşturmasıdır. "Stunning" tanisal ${ }^{131}$ I uygulamasından 48-72 saat sonra tiroit hücrelerinde muhtemelen "Na-I symporter" (NIS) mRNA düzeyinin düşmesine bağlı takiben verilen ${ }^{131} \mathrm{I}$ alımının azalmasıdır (McDougall ve Lagaru, 2011). ${ }^{123}$ I veya ${ }^{131} \mathrm{I}$ ile tanısal tüm vücut iyot tarama çalışmasının yapılması kararı "American Thyroid Association" (ATA) k1lavuzuna göre tedavi kararı ya da verilecek dozu etkileyeceği düşünülüyorsa alınmalıdır. Ancak bu durumda eğer ${ }^{131}$ I kullanıldıysa ablasyon dozu 72 saat içinde verilmelidir. Bundan amaç "stunning" oluşmadan tedavi dozunun verilmesidir. "National Comprehensive Cancer Network" (NCCN) farklı bir yaklaşım göstermekte ve ablasyon düşünülen hastalarda tanısal iyot tarama çalışması yapılmasını önermektedir (Tuttle ve ark., 2012).

Uzak metastaz varlığında; $100-250 \mathrm{mCi}$ arasında ${ }^{131} \mathrm{I}$ dozu kullanılabilir (Henkin ve ark., 2011). Ampirik olarak, servikal lenf nodu metastazı için 150-175 mCi, akciğer metastazı için 175-200 mCi, kemik metastazı için $200 \mathrm{mCi}$ kullanılabilir (Silberstein ve ark., 2006). 
Tablo 1. Son k1lavuzlarda diferansiye tiroit kanserlerinde RAİ ablasyon endikasyonları

Kılavuz

Önerilir

Yapılabilir

Uzak metastaz, gros tiroit dışı tümör yayılımı veya primer tümör çapı $>4 \mathrm{~cm}$

ATA Primer tümör çapı $<4 \mathrm{~cm}$ olanlarda $\rightarrow$ lenf nodu metastazı veya diğer yüksek risk faktörleri

değerlendirildiğinde nüks/ölüm riski orta-yüksek risk grubundaysa

LATS

Yaşı >45 olanlarda T3/T4 tümör, N1, cerrahi sonrası rezidü tümör, tiroit kapsülü dışına tümör yayılımı / rezidü hastalık, M1, agresif tümör histolojisi

T1 $>1 \mathrm{~cm}$, multifokal T1/T2

ESMO

T3/T4, N1 veya M1

T1 $>1 \mathrm{~cm} / \mathrm{T} 2$, multifokal T1, agresif histoloji

ATA: American Thyroid Association (Cooper ve ark., 2009)

LATS: Latin America Thyroid Association (Pitoia ve ark., 2009)

ESMO: European Society of Medical Oncology (Pacini ve ark., 2010)

Dozimetrik veya ampirik yöntemlerle tedavi edilen hastalarda benzer başarı oranları elde edilmiştir (Maxon ve ark., 1992). Yüksek dozlar kullanıldığında kemik iliği süpresyonu ve özellikle yaygın akciğer metastazı olanlarda tedaviye bağlı pnömonitis/fibrozis olabilmektedir (Henkin ve ark., 2011). Akciğer fonksiyonlarında kısıtlılık varsa tedavi öncesi solunum fonksiyon testleri ile değerlendirilmelidir. Lezyon boyutu tedaviye yanıt öngörüsünde önemli bir parametredir (Silberstein, 2006). Boyutları 1-2 cm'den büyük olanlarda başarı oranı mikroskobik ya da küçük metastazlara göre daha düşüktür. RAİ tedavisi tolere edilemeyen yan etkiler yoksa ${ }^{131} \mathrm{I}$ pozitif metastazlar yok oluncaya kadar devam ettirilebilir (Şek. 5,6) (Luster ve ark., 2008). Kümülatif ${ }^{131}$ I dozunda üst sınır yoktur. Toplam doz $22 \mathrm{GBq}$ (yaklaşık $600 \mathrm{mCi}$ ) olduğunda birçok hasta remisyona girer (Durante ve ark., 2006). Bu dozun üstünde tedaviye devam etmek için, hastalar miyelosüpresyon başta olmak üzere olası yan etkiler yönünden bireysel olarak değelendirilmelidir. Birkaç doz sonrası tam yanıt alınmayan ancak stabil olan hastalar için tedavi dozları arası süre uzatılabilir ya da bekle-gör politikası uygulanabilir (Luster ve ark., 2008). Tedavi ya da tanısal amaçla ${ }^{131} \mathrm{I}$ içirilmeden önce endojen yolla tiroit hormon preparatları kesilerek veya rekombinant TSH ile stimülasyon yapılmalıdır. Endojen TSH stimülasyonu seçildiğinde doz verilmeden 4-5 hafta önce levotiroksin (LT4) preparat1 kesilmeli veya LT4 yerine uygulamadan iki hafta önce kesilmek üzere LT3 preparatına başlanmalıdır (Luster ve ark., 2008).

İyi diferansiye tiroit kanserli hastaların bazıları takipte Tg pozitifliği gösterirken tanısal ${ }^{131}$ I tüm vücut tarama çalışmasında patolojik odak izlenmeyebilir. "Tg elevation/ negative iodine scintigraphy" (TENIS) sendromu olarak adlandırılan bu durum hücrelerin fonksiyon kaybı nedeniyle oluşur (Şek. 7) (Silberstein, 2011); Yaş1 45'in üzerinde olanlarda mutasyonla NIS fonksiyon kaybı olması Tg üreten rezidü tiroit ya da malign hücrelerin iyot alımını engeller. AntiTg antikor pozitifliği Tg değerlendirmesinde genellikle yanlış negatiflik nedeni olsada bazen $\mathrm{Tg}$ düzeylerinde artışa neden olarak yanlış pozitiflik nedeni de olabilmektedir. TENIS sendromu ayırıcı tanısında anti Tg Ab pozitifliği yanı sıra stabil iyot havuzunda artışa bağlı radyoaktif iyot dilüsyonu göz önüne alınmalıdır.

TENIS sendromunda tanısal iyot tüm vücut taramanın yeri yoktur. Nüks/metastaz araştırmasında radyolojik yöntemler (iyotlu kontrast içermeyen) ya da ${ }^{18} \mathrm{~F}$ florodeoksiglikoz (FDG) PET/BT kullanılabilir (Şek. 7,8). Rezektabl odak saptanmazsa 100-150 mCi RAİ ampirik olarak uygulanabilir (Henkin ve ark., 2011). Bu olguların bazılarında yüksek doz uygulamalarında iyot alımı izlenebilmekte ve takiben Tg düzeylerinde düşme olabilmektedir (Ma ve ark., 2005). Bu grup hastalarda retinoik asit, resveratrol, rosiglitazone gibi bazı ajanlar, hücreleri rediferansiye ederek iyot yakalama yeteneği kazandırmak amacıyla kullanılmış ama sınırlı başarı sağlanmıştır (Kebebew ve ark., 2009; Morris, 2010).

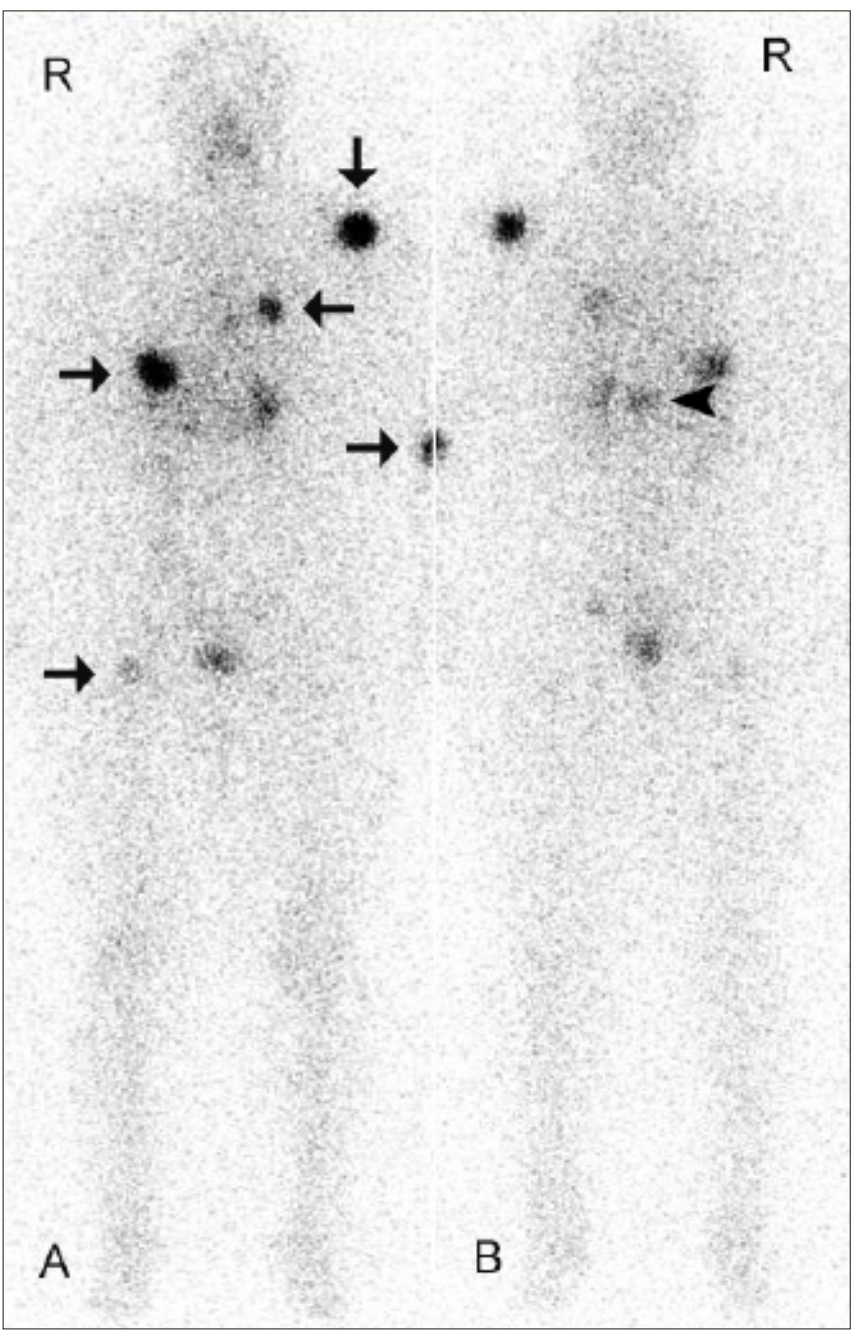

Şek. 5. Multipl odakta metastaz. Foliküler tiroit kanseri nedeniyle izlenen 46 yaşında kadın hastanın $\mathrm{TSH}=100 \mu \mathrm{IU} / \mathrm{mL}, \mathrm{Tg}=>300 \mathrm{ng} / \mathrm{mL}$, Anti $\mathrm{Tg}$ $\mathrm{Ab}=10$ iken yapılan tüm vücut ${ }^{131} \mathrm{I}$ sintigrafisinde sol omuzda, sol dirsekde, sağ femur proksimalinde, toraksta 2 odakta (ok) ve torakal vertebralarda (ok başı) olmak üzere metastaz ile uyumlu madde akümülasyonları vardır (A: Anterior, B: Posterior, $\mathrm{R}$ : Să̆) 


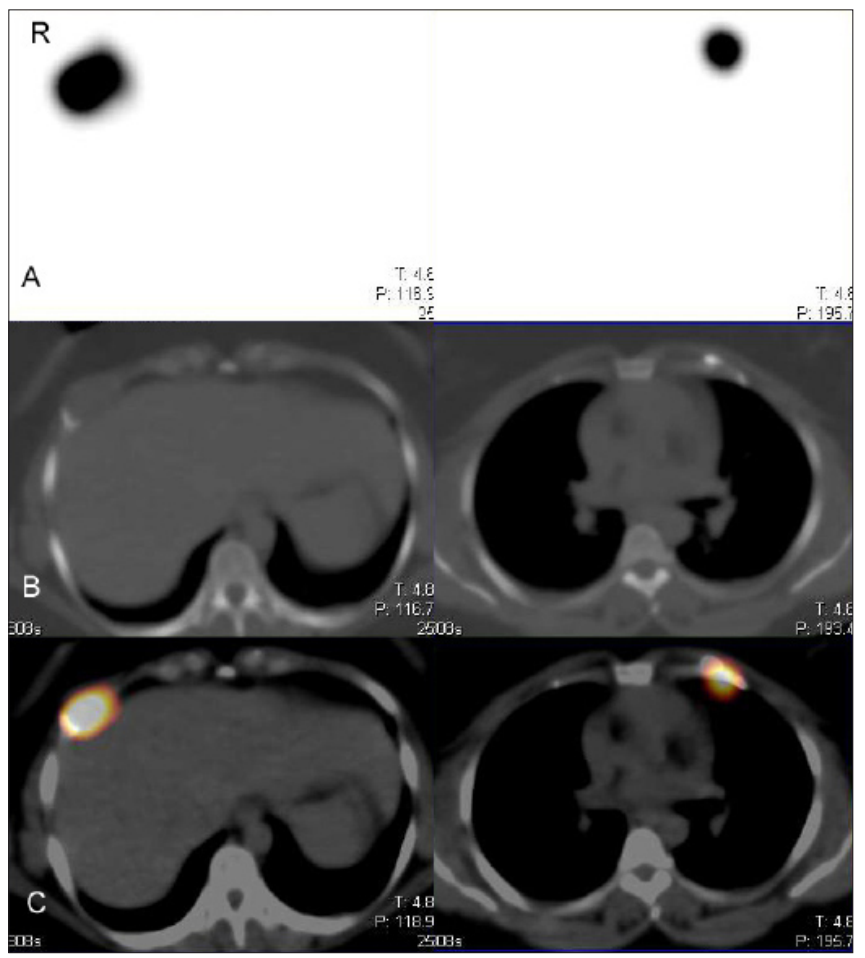

Şek. 6. Multipl odakta metastaz, SPECT/BT katkısı. Yeni teknolojik bir gelişim olan hibrid cihazlar ile tomografik sintigrafik (SPECT) görüntüler (fonksiyonel) BT'den elde edilen (morfolojik) görüntüler ile birleştirilerek ${ }^{131} \mathrm{I}$ pozitif odakların anatomik lokalizasyonu yapılabilmektedir. Resim 4'deki hastanın tüm vücut taramasını takiben torakal bölgeden yapılan SPECT/BT çalışmasında toraksta iki odakta tanımlanan ${ }^{131} \mathrm{I}$ madde akümülasyonlarının kostalardaki litik odaklar ile uyumlu olduğu izlenmektedir (A: ${ }^{131}$ I SPECT çalışması kesitleri, B: BT kesitleri, C: SPECT/ BT füzyon kesitleri, R:Sağ).

Medüller tiroitkarsinomu; parafolikülerhücrelerdenköken alır. İyot alımı göstermediğinden RAİ tedavisinin kullanımı sinırlıdır. Tiroidektomi ve lenf nodu diseksiyonunu takiben RAİ uygulandığında muhtemelen foliküllerde akümüle olan ${ }^{131}$ I' in komşu tümör hücrelerini etkilemesine bağlı olarak kalsitonin seviyelerinde düşme bildirilmiștir (Clarke, 1991). $\mathrm{Bu}$ tümörün somatostatin reseptörü ekspresyonu göstermesi nedeniyle tedavisinde Y-90 DOTATOC veya Lu-177 DOTATATE radyopeptidleri kullanılabilir (Biermann ve ark., 2011). Bir diğer tedavi ajanı norepinefrin analoğu olan meta iyodobenzil guanidin'dir (MIBG). Progresyon gösteren veya kalsitonin nedeni ile diare oluşan hastalarda 200-300 mCi dozunda ${ }^{131} \mathrm{I}$ MIBG ile, progresyon gösteren veya kalsitonin nedeni ile diare oluşan hastalarda tedavi yapılabilir (Biermann ve ark., 2011). Hastaların yaklaşık 1/3'ünde tedavi başarılı olmaktadır. Hastaların cerrahi/kemoterapi şansı olmaması ve tanısal çalışmada MIBG alımı göstermesi gerekir.

RAİ tedavisini takiben tiroit bezinde fibrozise kadar giden histopatolojik değişiklikler kademeli olarak oluşur. Verilen doz 30-150 mCi ${ }^{131}$ I ise uygulamay1 takiben (Harpert ve ark., 1987); erken dönemde tiroit bezinde stromal ödem, nüklear piknozis ve epitelyal sitoplazmada granülarite görülür. Foliküler boyutta azalma ve foliküllerin konnektif doku ile yer değiştirmesi 40 gün civarında, lenfositik infiltrasyon 4080 gün civarında görülür.

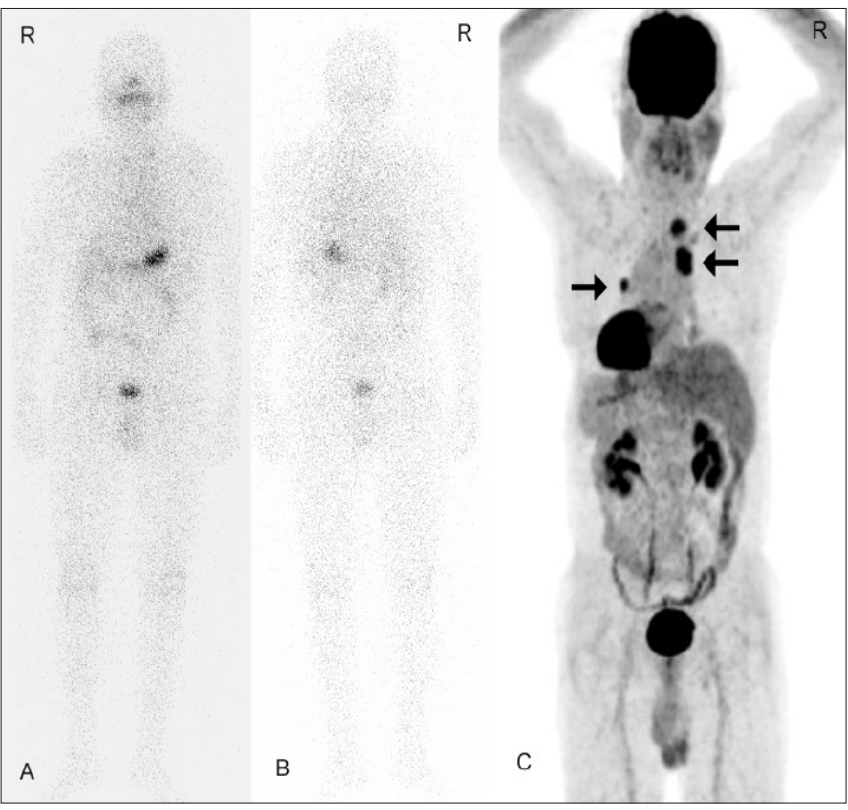

Şek. 7. TENIS sendromu. Tiroit papiller kanseri nedeniyle tiroidektomi yapılan 70 yaşında erkek hastada $\mathrm{Tg}$ yüksekliği (TSH=50,92, Tg=72,1 ng/mL, Anti Tg $A b=6,43 \mathrm{IU} / \mathrm{mL}$ ) varken tanısal I-131 tüm vücut sintigrafisinde patolojik odak izlenmedi (A: Anterior, B: Posterior, R:Sağ). ${ }^{18} \mathrm{~F}$ FDG PET/ BT çalışması maksimum intensite görüntüsünde sağ servikal alanda, mediastende ve sol akciğerde patolojik odaklar izlenmektedir (C).

Takiben, fibroz stroma içinde birkaç foliküler hücre ve fragmante kolloid saptanır. Fibrozis birkaç yıl progresif olarak sürer.

RAİ tedavisininden sonra doza bağımlı ve erken dönemde görülen yan etkiler oluşabilir. Bunların bazıları baş ağrısı, bulantı ve kusma gibi birkaç saat içinde başlayan ve 2-3 günde düzelen semptomlardır. ${ }^{131} \mathrm{I}$, fizyolojik olarak tükürük bezlerinde akümüle olduğundan \% 30 insidansla sialadenit ve yüksek dozlarda nadiren oluşan ağız kuruluğu; geçici tat ve koku bozuklukları oluşabilir (Luster ve ark., 2008). Tedavi sonrası bol su alımı ve tükürük sekresyonunu artırıcı girişimler yan etkileri azaltabilir. Miyelosüpresyon ve buna bağlı pansitopeni 200 cGy üzerinde kemik iliği dozları alındığında ortaya çıkar. RAİ dozu 150-200 mCi düzeyini aşınca geçici miyelosüpresyon görülebilir (Henkin ve ark., 2011). Miyelosüpresyon insidansı kemik metastazları olduğunda ve yüksek kümülatif ${ }^{131}$ I dozları alındığında artar. Doğurganlık çağındaki kadın hastaların RAİ tedavisi sonrası 6-12 ay, erkek hastaların ise sperm kalitesindeki geçici azalma nedeniyle dört ay kontrasepsiyon uygulaması önerilmektedir (Reiners ve ark., 2008). Kadınlarda 600 mCi'yi aşan kümülatif dozlar fertilitede azalmaya neden olabilir (Henkin ve ark., 2011). Gonadların aldığı radyasyon dozunu azaltmak için tedavi sonrası dönemde bol su içilmesi ve sık miksiyon yapılarak mesanenin boşaltılması gereklidir. Beyin metastazı olanlarda tedaviyi takiben serebral ödem görülebilir (Silberstein, 2006).

İyonizan radyasyon bilinen kanser nedenlerinden birisidir. RAİ tedavisi alanlarda ikinci primer kanser insidansında artış olduğu bildirilmektedir (Iyer ve ark., 2011). Radyasyona bağlı lösemi ve solid kanser (tükürük bezi, böbrek, mesane ve gastrointestinal kanser) oluşumu riski kümülatif olarak 


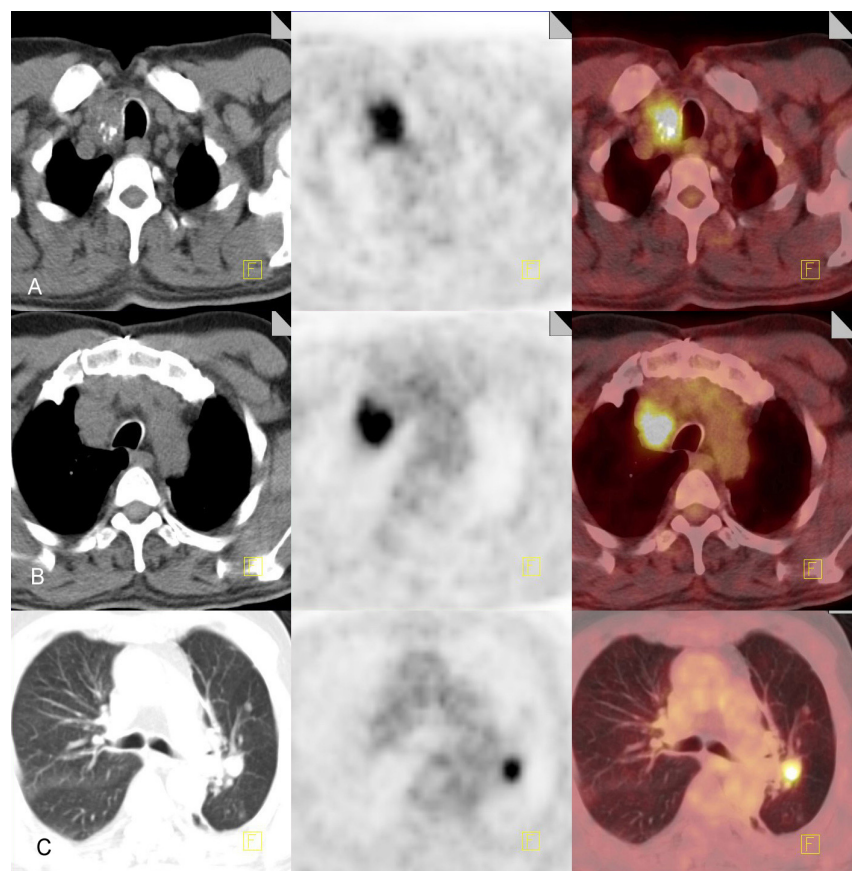

Şek. 8. TENIS sendromu. Resim 7'deki hastanın PET/ BT çalışmasının kesitsel görüntülerinde (sırasıyla BT, PET ve PET/BT füzyon kesitleri) servikal bölgede sağ tiroit lobu loju inferior bölümünde (A), mediastende sağ paratrakeal lenf nodlarında (B) ve sol akciğerdeki nodülde patolojik ${ }^{18} \mathrm{~F}$ FDG akümülasyonları vardır.

300-400 mCi RAİ tedavisi alanlarda artmaktadır (Henkin ve ark., 2011). Tiroit kanseri tanılı RAİ tedavisi alan 6841 hasta incelendiğinde kemik, yumuşak doku, kolon ve rektum maligniteleri ile lösemi insidansında doza bağımlı artış olduğu gösterilmiştir (Rubino ve ark., 2003). Buna karşın 10000 RAİ tedavisi alan hasta ve 19000 kontrolden oluşan çalışma grubunda ${ }^{131}$ I uygulamasına bağlı sekonder tümör riskinde artış saptanmamıştır (Bhattacharyya ve ark., 2006). Literatürde farklı sonuçlar olmakla birlikte birden fazla yüksek doz uygulamalarında kümülatif doz göz önüne alınarak karar verilmesi uygun olacaktır.

Hamilelik ve laktasyon dönemi RAI uygulaması için kontrendikedir (Luster ve ark., 2008; Cooper ve ark., 2009). Doğurganlık çağındaki kadınlar RAİ uygulaması öncesi hamileliğin varlığı yönünden sorgulanmalıdır. Laktasyon döneminde iyotun sütle sekresyonu nedeniyle memelerin aldığ 1 radyasyon dozunu azaltmak ve bebeğin korunması amacıyla ${ }^{131} \mathrm{I}$ uygulaması yapılmamalıdır. Kemik iliği süpresyonu olanlarda yüksek doz RAİ uygulaması, akciğer fonksiyonlarında kısıtlılık olanlarda akciğer metastazlarında belirgin ${ }^{131} \mathrm{I}$ akümülasyonu beklentisi, nörolojik bulgular varlığında beyin metastazlarının RAİ tedavisine bağlı ciddi kompresyon etkisi oluşturacağı düşünülenlerde RAİ tedavisi göreceli kontrendikedir (Luster ve ark., 2008).

Türkiye'de $800 \mathrm{MBq}$ 'in (21 mCi) üzerinde radyoaktif iyot tedavisi standartlara uygun ve Türkiye Atom Enerjisi Kurumu tarafindan lisans verilen sıvı atık sistemi ve izolasyonlu oda bulunan yerlerde yapılabilmektedir. Hastalar, vücutlarında kalan aktivite $600 \mathrm{MBq}(16 \mathrm{mCi})$ ve bir metre uzaktan ölçüm değeri 30 mikroSievert/saat'in altına düşünce diğer kişilerin radyasyondan korunması için gerekli bilgilendirme yapıldıktan sonra taburcu edilebilir (Radyasyon Güvenliği Yönetmeliği, 2004).

Hipertiroidi ve iyi diferansiye tiroit kanserinde RAİ kullanımı uzun zamandır kullanılan, efektif, yan etkileri az ve genellikle sinırlı olarak izlenen ve kolay uygulanan bir tedavi yöntemidir. Ancak, her tedavi kararından önce hastaya özel değerlendirme yapılmalı, en uygun doz seçilmeli ve gerektiğinde alternatif tedavi yöntemleri de göz önüne alınmalıdır.

\section{KAYNAKLAR}

Bachmann, J., Kobe, C., Bor, S., Rahlff, I., Dietlein, M., Schicha, H., Schmidt, M., 2009. Radioiodine therapy for thyroid volume reduction of large goitres. Nucl. Med. Commun. 30, 466-471.

Bahn, R.S., Burch, H.B., Cooper, D.S., Garber, J.R., Greenlee, M.C., Klein, I., Laurberg, P., McDougall, I.R., Montori, V.M., Rivkees, S.A., Ross, D.S., Sosa, J.A., Stan, M.N., 2011. Hyperthyroidism and other causes of thyrotoxicosis: Management guidelines of the American Thyroid Association and American Association of Clinical Endocrinologists. Thyroid. 21, 593-647.

Bhattacharyya, N., Chien, W., 2006. Risk of second primary malignancy after radioactive iodine treatment for differentiated thyroid carcinoma. Ann. Otol. Rhinol. Laryngol. 115, 607-610.

Bal, C.S., Kumar, A.., Pant, G.S., 2004. Radioiodine dose for remnant ablation in differentiated thyroid carcinoma: A randomized clinical trial in 509 patients. J. Clin. Endocr. Metab. 89, 1666-1673.

Bartalena, L., Baldeschi, L., Dickinson, A., Eckstein, A., Taylor, P.K., Marcocci, C., Mourits, M., Perros, P., Boboridis, K., Boschi, A., Curro, N., Daumerie, C., Kahaly, G.J., Krassas, G.E., Lane, C.M., Lazarus, J.H., Marino, M., Nardi, M., Neoh, C., Orgiazzi, J., Pearce1, S., Pinchera, A., Pitz, S., Salvi, M., Sivelli, P., Stahl, M., Arx, G.V., Wiersinga, W.M., 2008. Consensus statement of the European Group on Graves' orbitopathy (EUGOGO) on management of GO. Eur. J. Endocrinol. 158, 273-285.

Biermann, K., Biersack, H.J., Sabet, A., Janzen, V. 2011. Alternative therapeutic approaches in the treatment of primary and secondary dedifferentiated and medullary thyroid carcinoma. Semin. Nucl. Med. 41, 139-148

Canadas, V., Vilar, L., Moura, E., Brito, A., Castellar, E., 2007. Evaluation of radioiodine therapy with fixed doses of 10 and $15 \mathrm{mCi}$ in patients with Graves' disease. Arq. Bras. Endocrinol. Metab. 51, 1069-1076.

Chianelli, M., Todino, V., Graziano, F., Panunzi, C., Pace, D., Guglielmi, R., Signore, A., Papini, E., 2009. Low dose (2.0 GBq; 54 mCi) radioiodine postsurgical remnant ablation in thyroid cancer: Comparison between hormone withdrawal and use of rhTSH in low risk patients. Eur. J. Endocrinol. 160, 431-436.

Clarke, S.E.M., 1991. Radionuclide theraphy of the thyroid. Eur. J. Nucl. Med. 18, 984-991.

Collier, A., Gosh, S., Hair, M., Malik, I., McGarvie, J., 2009. Comparison of two fixed activities of radioiodine therapy (370 vs. 555 MBq) in patients with Graves' disease. Hormones. 8, 273-278.

Cooper, D.S., Doherty, G.M., Haugen, B.R., Kloos, R.T., Lee, S.L., Mandel, S.J., Mazzaferri, E.L., McIver, B., Pacini, F., Schlumberger, M., Sherman, S.I., Steward, D.L., Tuttle, R.M., 2009. Revised American thyroid association management guidelines for patients with thyroid nodules and differentiated thyroid cancer. Thyroid. 19, 1-48.

Durante, C., Haddy, N.,Baudin, E., Leboulleux, S., Hartl, D., Travagli, J.P., Caillou, B., Richard, M., Lumbroso, J.D., De Vathaire, F., Schlum- 
berger, M., 2006. Long-term outcome of 444 patients with distant metastases from papillary and follicular thyroid carcinoma: Benefits and limits of radioiodine therapy. J. Clin. Endocr. Metab. 91, 2892-2899.

Elgazzar, A.H., Al-Bader, A., 2006. Basis of therapeutic nuclear medicine. In The Pathophysiologic Basis of Nuclear Medicine. A.H. Elgazzar, ed., 2nd edition, Springer-Verlag, Berlin, Heidelberg, New York, pp 521-539.

Gupta, S.K., McGrath, S., Rogers, K., Attia, J., Lewis, G., Viswanathan, S., Saul, M., Allen, L., 2010. Fixed dose radioiodine for the treatment of hyperthyroidism: Outcome and its predictors. Intern. Med. J. 40, 854-857.

Harbert, J.C., Robertson, J.S., Held, K.D., 1987. Nuclear Medicine Theraphy. Thieme, New York.

Henkin, R.E., Del Rowe, J.D., Grigsby, P.W., Hartford, A.C., Jadvar, H., Macklis, R.M., Parker, J.A., Wong, J.Y., Rosenthal, S.A., 2011. ACRASTRO Practice guideline for the performance of therapy with unsealed radiopharmaceutical sources. Clin. Nucl. Med. 36, 72-80.

Hertz, S., Roberts, A., 1942. Radioactive iodineas indicator in thyroid physiology: Use of radioactive iodine in differential diagnosis of 2 types of Grave's Disease. J. Clin. Invest. 21, 31-32.

Huysmans, D.A., Corstens, F.H., Kloppenborg, P.W., 1991. Long-term follow up in toxic solitary autonomous thyroid nodules treated with radioactive iodine. J. Nucl. Med. 32, 27-39.

Iagraru, A., McDougall, I.R., 2007. Treatment of thyrotoxicosis. J. Nucl. Med. 48, 379-389.

Iyer, N.G., Morris, L.G.T., Tuttle, R.M., Shaha, A.R., Ganly. I., 2011. Rising incidence of second cancers in patients with low-risk (T1N0) thyroid cancer who receive radioactive iodine therapy. Cancer. 117, 4439-4446.

Kebebew, E., Lindsay, S., Clark, O.H., Woeber, K.A., Hawkins, R., Greenspan, F.S., 2009. Results of rosiglitazone therapy in patients with thyroglobulin-positive and radioiodine-negative advanced differentiated thyroid cancer. Thyroidology. 19, 953-956.

Kowalsky, R.J., Perry, J.R., 1987. Radipharmaceuticals in Nuclear Medicine Practice. Appleton and Lange, Connecticut. 181-210.

Leslie, W.D., Ward, L., Salamon, E.A., Ludwig, S., Rowe, R.C., Cowden, E.A., 2003. A randomized comparison of radioiodine doses in Graves' hyperthyroidism. J. Clin. Endocr. Metab. 88, 978-983.

Luster, M., Clarke, S.E., Dietlein, M., Lassmann, M., Lind, P., Oyen, W.J.G., Tennvall, J., Bombardieri, E., 2008. Guidelines for radioiodine therapy of differentiated thyroid cancer. Eur. J. Nucl. Med. Mol. Imaging. 35, 1941-1959.

Ma, C., Xie, J., Kuang, A., 2005. Is empiric I-131 therapy justified for patients with positive thyroglobulin and negative I-131 whole body scanning results? J. Nucl. Med. 46, 1164-1170.

Maxon, H.R., Englaro, E.E., Thomas, S.R., Hertzberg, V.S., Hinnefeld, J.D., Chen, L.S., Smith, H., Cummings, D., Aden, M.D., 1992. Radioiodine-131 therapy for well-differentiated thyroid cancer: A quantitative radiation dosimetric approach-Outcome and validation in 85 patients. J. Nucl. Med. 33, 1132-1137.

Maxon, H.R., Smith, H.S., 1990. Radioiodine-131 in the diagnosis and treatment of metastatic well-differentiated thyroid cancer. Endocrinol. Clin. North. Am. 19, 685-718.

McDougall, R., Lagaru, A., 2011. Thyroid stunning: Fact or fiction? Semin. Nucl. Med. 41,105-112.

Meier, D.A., Dworkin, H.J., Bender, J.M., 2006. Therapy for hyperthyroidism. In Nuclear Medicine, Vol. 2, R.E. Henkin, ed. 2nd edition. Mosby, Philadelphia, pp. 1567-1575.

Morris, J.C., 2010. Resveratrol, thyroid cancer and iodide: Drink up? Thyroid. 20, 125-126.

Nostrand, D.V., Aiken, M., Atkins, F., Moreau, S., Garcia, C., Acio, E., Burman, K., Wartofsky, L., 2009. The utility of radioiodine scans prior to iodine 131 ablation in patients with well-differentiated thyroid cancer. Thyroid. 19, 849-855.

Nygaard, B., Hegedus, L., Nielsen, K.G., Ulriksen, P., Hansen, J.M., 1999. Long-term effect of radioactive iodine on thyroid function and size in patients with solitary autonomously functioning toxic thyroid nodules. Clin. Endocrinol. 50,197-202.

Pacini, F., Castagna, M.G., Brilli, L., Pentheroudakis, G., 2010. Tyhroid cancer: ESMO Clinical Practice Guidelines for diagnosis. Treatment and follow-up. Ann. Oncol. 21, 214-219.

Peters, H., Fischer, C., Bogner, U., Reiners, C., Schleusener, H., 1995. Radioiodine therapy of Graves' hyperthyroidism: Standard vs. calculated 131 iodine activity. Results from a prospective, randomized, multicentre study. Eur. J. Clin. Invest. 25, 186-193.

Pitoia, F., Ward, L., Wohllk, N., Friguglietti, C., Tomimori, E., Gauna, A., Camargo, R., Vaisman, M., Harach,R., Munizaga, F., Corigliano, S., Pretell, E., Niepomniszcze, H., 2009. Recommendations of the Latin American Thyroid Society on diagnosis and management of differentiated thyroid cancer. Arq Bras Endocrinol Metab. 53, 884-897.

Porterfield J.R., Thompson, G.B., Farley, D.R., Grant, C.S., Richards, M.L., 2008. Evidence-based Management of Toxic Multinodular Goiter (Plummer's Disease). World J. Surg. 32,1278-1284.

Radyasyon güvenliği yönetmeliğinde değişiklik yapılmasına dair yönetmelik, Madde 7. T.C. Resmi Gazete, 25598, 29 Eylül 2004.

Read, C.H., Tansey, M.J., Menda, Y., 2004. A 36-year retrospective analysis of the efficacy and safety of radioiodine in treating young Graves' patients. J. Clin. Endocr. Metab. 89, 4229-4233.

Reiners, C., Dietlein, M., Luster, M., 2008. Radio-iodine therapy in differentiated thyroid cancer: Indications and procedures. Best Pract Res Clin Endocrinol Metab. 22, 989-1007.

Ron, E., Doody, M.M., Becker, D.V., Brill, A.B., Curtis, R.E., Goldman, M. B., Haris, B.S.H., Hoffman, D.A., McConahey,W.M., Maxon, H.R., Preston-Martin, S., Warshauer, M.E., Wong, F.L., Boice, J.D., 1998. Cancer mortality following treatment for adult hyperthyroidism. JAMA. 280, 347-355.

Ross, D.S., Ridgway, E.C., Daniels, G.H., 1984. Successful treatment of solitary toxic thyroid nodules with relatively low-dose iodine-131, with low prevalence of hypothyroidism. Ann. Intern. Med. 101, 488-490.

Rubino C., de Vathaire, F., Dottorini, M.E., Hall, P., Schvartz, C., Couette J.E., Dondon, M.G., Abbas, M.T., Langlois, C., Schlumberger, M., 2003. Second primary malignancies in thyroid cancer patients. Br. J. Cancer. 89, 1638-1644.

Salvatori, M., Luster, M., 2010. Radioiodine therapy dosimetry in benign thyroid disease and differentiated thyroid carcinoma. Eur J Nucl Med Mol Imaging. 37,821-828.

Silberstein, E.B., 2011. The problem of the patient with thyroglobulin elevation but negative iodine scintigraphy: The TENIS syndrome. Semin. Nucl. Med. 41, 113-120.

Silberstein, E.B., 2006. The treatment of thyroid malignant neoplasms. In Nuclear Medicine, Vol. II , R.E. Henkin, ed., 2nd edition, Mosby Elsevier, Philadelphia, pp.1576-1587.

Stokkel, M.P.M., Handkiewicz, J., Lassman, M., Dietlein, M., Luster, M., 2010. EANM procedure guidelines for therapy of benign thyroid disease. Eur J Nucl Med Mol Imaging. 37, 2218-2228.

Tallstedt, L., Lundell, G., Tørring, O., Wallin, G., Ljunggren, J.G., Blomgren, H., Taube, A., 1992. Occurrence of ophthalmopathy after treatment 
for Graves' hyperthyroidism. N. Engl. J. Med. 326, 1733-1738.

Tuttle, R.M., Ball, D.W., Byrd, D., Dilawari, R.A., Doherty, G.M., Duh, Q.Y., Ehya, H., Farrar, W.B., Haddad, R.I., 2012. The NCCN Thyroid Carcinoma Panel Members. National Comprehensive Cancer Network Clinical Practice Guidelines in Oncology: Thyroid Carcinoma V.2.2012. www.nccn.org. Date: 14/01/2012.

Tzavara, I., Tzanela, M., Vlassopoulou, B., Kouyiomoutzakis, G., Kyriazopoulou, V., Alevizaki, C., Thalassinos, N.C., 2002. Long term thyroid function after (131)I treatment for toxic adenoma. Hormones. 1, 99-103.

Von Hofe, S.E., Dorfman, S.G., Carretta, R.F., Young, R.L., 1978. The increasing incidence of hypothyroidism within one year after radioiodine therapy for toxic diffuse goiter. J. Nucl. Med. 19, 180-184.

Wartofsky, L., Glinoer, D., Solomon, B., Nagatak1, S., Lagasse, R., Nagayama, Y., Izum1, M., 1991. Differences and similarities in the diagnosis and treatment of Graves disease in Europa, Japan and the United States. Thyroid. 1, 129-135.

Yano, Y., Sugino, K., Akaishi, J., Uruno, T., Okuwa, K., Shibuya, H., Kitagawa, W., Nagahama, M., Ito, K., 2011. Treatment of autonomously functioning thyroid nodules at a single institution: radioiodine therapy, surgery, and ethanol injection therapy. Ann. Nucl. Med. 25, 749754.

Zakavi, S.R., Mousavi, Z., Davachi, B., 2009. Comparison of four different protocols of I-131 therapy for treating single toxic thyroid nodule. Nucl. Med. Commun. 30, 169-175.

Zimmermann, R., 2007. Nuclear Medicine, Radioactivity for Diagnosis and Therapy. EDP Sciences, Cedex. 7-8. 